\title{
Men without Sperms
}

\section{Abayomi B. Ajayi' ${ }^{1}$ Bamgboye M. Afolabi2 ${ }^{*}$, Victor D. Ajayi' Ifeoluwa Oyetunji' Oluwafunmilola Biobaku${ }^{1}$, Adedamilola Atiba ${ }^{1}$}

\author{
${ }^{1}$ Nordica Fertility Centre, Lagos, Nigeria \\ ${ }^{2}$ Health, Environment and Development Foundation, Lagos, Nigeria \\ Email: ^bmafolabi@gmail.com
}

How to cite this paper: Ajayi, A.B., Afolabi, B.M., Ajayi, V.D., Oyetunji, I., Biobaku, O. and Atiba, A. (2018) Men without Sperms. Open Journal of Urology, 8, 25-42. https://doi.org/10.4236/oju.2018.81004

Received: October 17, 2017

Accepted: January 27, 2018

Published: January 30, 2018

Copyright $\odot 2018$ by authors and Scientific Research Publishing Inc. This work is licensed under the Creative Commons Attribution International License (CC BY 4.0).

http://creativecommons.org/licenses/by/4.0/

\section{(c) (i) Open Access}

\begin{abstract}
Introduction: Men without sperm (azoospermic) make up about 15\% of all infertile men in reproductive age of fatherhood. Male infertility is a health and social problem in many communities. Subjects and Methods. This retrospective study was carried from 2010 to 2015 . Initially, 907 men were included in the study among whom 109 (12.02\%), $346(38.15 \%)$ and $452(49.83 \%)$ were azoospermic, oligospermic and normospermic, respectively. This study only investigated the association between age, BMI, semen volume, liquefaction time and pus cells among normospermic and azoospermic men. Standard semen analysis was performed and subjects were categorized by age into $<30,30$ - 39.9, 40 - 49.9, 50 - 59.9 and $\geq 60$ years and by body mass index into normal (18.5 - 24.9), overweight $(25.0-29.9)$ and obese $(\geq 30)$. Results. The 562 subjects of the study had means ( \pm sd) age of $42.6( \pm 7.10)$ years and BMI of 27.0 (4.1) $\mathrm{kg} / \mathrm{m}^{2}$ respectively. In all, 109 (19.4\%) were azoospermic. Overweight and obese men were, respectively, more than $1^{1 / 2}$ and about $2^{1 / 2}$ times more likely to be azoospermic compared to normal weight men. Azoospermic men were significantly heavier than men with normal sperm count $(\mathrm{t}=-0.34$; $\mathrm{P}$-value $=0.003)$. Among those with normal weight, liquefaction time was significantly shorter $(t=5.49, \mathrm{P}$-value $=0.000001)$ in azoospermic $(28.70 \mathrm{~min}$. $)$ than in men with normal sperm count (31.82 min.). Obese azoospermic men were about 4 times as likely to have high pus cells in semen than normal weight azoospermic men ( $\mathrm{OR}=3.82$; 95\% CI: 0.39, 37.01). Multivariate regression analysis shows a strong but negative coefficient correlation between sperm concentration and BMI (coef. $=-0.48$, Std Err. $=0.25$, P-value $=0.05$, 95\% CI: $-0.96,0.10)$. Conclusion: Our findings suggest that high BMI is associated with azoospermia. Azoospermia also did not seem to negatively impact liquefaction time.
\end{abstract}

\section{Keywords}

Azoospermia, Normal Sperm Concentration, Age, Body Mass Index, Male 
Infertility, Sub-Sahara Africa

\section{Introduction}

Male infertility, from African perspective, is not just male infertility from the viewpoint of the developed countries. Infertility, especially of the male, is a more serious cause of anxiety and concern which affect married couples resulting in quiet stigmatization and loss of status within the family circuit and in the community at larger. Infertility of either male or female or of both is becoming a serious health problem affecting about $10 \%$ of all families worldwide [1] and possibly more in developing countries [2], probably as high as $25 \%$. Infertility is the inability of a sexually active, non-contracepting couple to achieve spontaneous pregnancy in one year [3] and azoospermia, broadly speaking, is the absence of sperm in the ejaculate [4]. The World Health Organization recommends that in such cases of absence of spermatozoa in wet preparation(on microscopic examination), the seminal fluid from which the sample came should be centrifuged at $3000 \times$ or more for 15 minutes and then examined again [3]. If a minimum quantity of spermatozoa is observed in either of the centrifuged samples, this is referred to as cryptozoospermia while the complete absence of spermatozoa is defined as azoospermia. Both sexes are affected by infertility, a health burden of some epidemiological proportion. In approximately $50 \%$ of couples with involuntarily childlessness, male-infertility-associated factor is observed together with abnormal semen parameters [5]. Fertile partners may recompense for fecundity problem of the man and thus infertility usually manifests if both partners are sub-fertile [3]. Recently, an exponential increase in the responsibility of male factor in couple's infertility has been observed and this could be attributed to comprehensive evaluation of the entire reproductive system of the male, the function of each part of that system and improved diagnostic tools [6]. There are a variety of conditions that may inhibit spermatogenesis and diminish the production and quality of sperm thus causing azoospermia. Azoospermia may also occur because of a reproductive tract obstruction. A study has classified azoospermia into three primary categories: 1) pre-testicular, 2) testicular, and 3) post-testicular, speculating that, though 1) and 3) etiology of azoospermia are generally manageable, 2) is generally not [7]. Other studies suggested causes of male infertility, including azoospermia, as urogenital infections such as genito-urinary tract tuberculosis [8], or filarial orchitis [9]. It is claimed that male infertility, including azoospermia, also results from: 1) congenital or acquired urogenital abnormalities, 2) malignancies, 3) increased scrotal temperature (e.g. as a consequence of varicocele), 4) endocrine disturbances, 5) genetic abnormalities, and 6) immunological factors [3]. It is established that overweight and obesity have a negative impact on female fertility profile [10] but few studies have been able to track the fertility profile of males. It is heartening to know that Oates [11] studied the genetic basis of male 
reproductive failure and concluded that evolving therapies have allowed the use of sperm from men with spermatogenic compromise, obstructive azoospermia, and sperm functional deficiency, enabling these men to procreate when unable to do so naturally. In sub-Saharan Africa, women are most often blamed for infertility in matrimonial relationships where the occurrence of infertility is involuntary and where hardly is the fault laid on both or on the male [12]. In most African societies, the attitude, beliefs and cultural practices tend to exonerate men from inability to bear children. One of the most important aspects of life in most, if not all, African settings is the ability to father a child, or to be called a "mother", to continue the human lineage. Not being able to father a child from one woman often leads to serial relationships with other women. It is also a general but erroneous notion that the ability to have and sustain an erection and to engage in a heterosexual coitus with a woman means that men are fertile. Some men believe that just having penile erection or producing ejaculate of semen during sexual intercourse is enough to father a child which, in some cases, is contrary to the expected. That a man may not produce enough sperm is well documented [5] but not having sperm at all is a serious trepidation not only for the man but also for the family, the community and the physician. Sermondade, et al. [13] reported overweight and obesity as risk factors for azoospermia while Macdonald, et al. [14] believed no significant correlation exists between BMI and the semen parameters with the exception of normal sperm morphology and that overweight and obese men showed no significantly increased relative risk of abnormal semen parameters.

Infertility, in general, is a huge public health problem which has not been adequately addressed in Nigeria. Because infertility is a public health burden which affects the mental and social well-being of individuals and the family, it has been included in the national program for reproductive and child health in India [15] though not in many African countries. Studies have shown that about $1 \%$ of all men in the general population suffer from azoospermia, and azoospermic men constitute approximately $10 \%$ to $15 \%$ of all infertile men [7]. Studies have incriminated obesity (high body mass index) in adult male infertility [16] [17] [18] while others claim no significant correlation between body mass index and semen quality [19] [20] [21]. Azoospermia and oligospermia, relative to age and body mass index of the male, have not been studied to any appreciable extent in a Black African population. Data on the association between azoospermia and both age and body mass index is rare on the continent. However, data from most of these studies emanated from industrialized countries and extremely few have come from a Black African population. Clinicians in sub-Saharan Africa often meet overweight and obese patients and there is need for more scientific information to clarify the burden of overweight and obesity on male fertility, especially. Therefore, the primary aims of this study was, first to document the prevalence of azoospermia among infertile males in a facility setting and to explore the effect of age, of BMI and of BMI for each age group, on men with normal 
sperm concentration and on those who have no sperms.

\section{Subjects and Methods}

This study was approved by the State Ethics Committee. The study took place at Nordica fertility Center in Lagos from 2010 to 2015. The Medical records of men aged 23 - 73, who presented because of infertility at three Nigerian cities-Lagos, Asaba and Abuja-were retrieved, entered into a laptop computer, cleaned and analyzed. Of the initial 602 couples 571 (94.8\%) males escorted their female spouses at their first consultation, and although all 571 were requested to produce semen for examination, only 562 (98.4\%) did, under stringent compliance with World Health Organization regulations for semen analysis [22]. Of the remaining 9, 4 (44.4\%) traveled out of the country, $2(22.2 \%)$ refused semen production due to fasting period at the duration of study; 2 (22.2\%) persons absconded and 1 (11.1\%) sperm sample was discarded because time of collection and days of abstinence were not provided. All the couples presented to the clinician because their wives were not getting pregnant after regular and constant unprotected sexual intercourse.

Semen samples were collected by masturbation, in a comfortable room provided with electricity, water, bathroom and air-conditioner, within a maximum of 3 - 5 minutes' walk to the laboratory and according to WHO specification [22]. The man was counseled to abstain from sex for a minimum/maximum duration of 2 - 5 days. The collected sterile semen sample was transported almost immediately to the laboratory for analysis within 30 minutes of production. Other relevant information given to each patient included: 1) accuracy in the semen collection, 2) semen should be collected in a wide-mouth measuring cylinder that was provided, and 3) the importance of reporting any loss of semen sample during collection. For this semen collection process, each patient was provided with a medical record form where data such as name, age (or date of birth), days of abstinence, date and time of collection, if there was any loss in semen volume during collection (incomplete collection) and the time of commencement of seminal fluid analysis in the laboratory were appropriately filled in by the patient and the laboratory staff who collected the semen sample.

Other anthropometric, social and medical/surgical records were also collected from the patients. These included weight (in $\mathrm{kg}$ ) and height (in $\mathrm{cm}$ ) for the determination of body mass index (BMI), marital status, occupation, smoking and alcohol use, groin operation, sexually transmitted diseases, as well as family and social history.

Within 30 minutes of production and collection at the laboratory and after liquefaction, semen samples were analyzed strictly according to WHO guidelines [22] to detect semen volume, total sperm concentration, motility, and morphology (reported elsewhere). The volume of the ejaculate was measured by directly reading it on a wide-mouth measuring cylinder provided for each patient. A volume of 3 - $5 \mu \mathrm{L}$ of semen sample was transferred to the center of the chamber; 
mean progressive motility was determined using light microscope $(\times 40)$ and was performed in 10 squares of the chamber, counting at least 200 spermatozoa and expressed as $10^{6}$ spermatozoa $/ \mathrm{ml}$. The total sperm count is the end concentration, expressed as $10^{6}$ spermatozoa $/ \mathrm{ml}$. After assessing sperm progressive motility in 100 random spermatozoa, these were described as 1) rapidly forward, fast progressive motility, 2) moderately forward, slow progressive motility, 3) jerky non-progressive motility, and 4) immotile/no movement. Other parameters assessed in the semen samples were color, viscosity, liquefaction time, pus cells per high power field and morphology. Age (years) was stratified into <30, 30 - 39.9, 40 - 49.9, 50 - 59.9 and $\geq 60$ and BMI was categorized according to WHO classification [23] as underweight (BMI < 18.5), normal weight (BMI 18.5 - 24.9), overweight (BMI 25.0 - 29.9) and obese (BMI $\geq 30$ ). Patients who were not on any medication that would interfere with spermatogenesis, those not consuming herbal medication and who gave consent for their semen to be analyzed were included into the study. Non-indigenes, those with history of fulminant infections or patients with neoplasm were excluded from the study. At further analysis stage, this study specifically focused on men with normal sperm count and those with azoospermia. Patients' confidentiality was assured by excluding any information such as age, address which could identify any patient with the study. Data were also coded and stored in a computer with password known only to the Principal Investigator.

Data were analyzed using STATA 13; associations between Age, BMI and Age-for-BMI with normal sperm concentration and with azoospermia were assessed using chi-square, Odds Ratio and 95\% Confidence Interval. Spearman correlation and analysis of variance (ANOVA), and a multiple linear regression analysis was performed to determine correlation coefficients and significance of means of two variables. In addition, the relative risks for men having azoospermia, giving reference range of the WHO [3], were calculated. A P-value of $\leq 0.05$ was taken as significant. Data were presented as Tables and bar charts.

\section{Results}

A total of 562 men, whose means $( \pm \mathrm{sd})$ of age (years) and BMI $\left(\mathrm{kg} / \mathrm{m}^{2}\right)$ were 42.6 (7.1) and 27.0 (4.1) respectively, were included in the study. Those aged $40-49$ years were in the highest proportion $(48.2 \%)$ while the least were those aged $<30$ years (1.1\%). None was classified as underweight while 171 (30.4\%), 294 (52.3\%) and $97(17.3 \%)$ were categorized as normal weight, overweight and obese respectively (Table 1). In all, 109 (19.4\%) of the 562 men were azoospermic, the majority of whom were aged $40-49.9$ years $(47,43.1 \%)$ (Figure 1$)$ or overweight $(60,64.2 \%)$. Table 1 and Figure 2 also show a significant difference $(\mathrm{t}=-2.70, \mathrm{P}$-value $=$ $0.004)$ in the BMI of azoospermic men $\left(28.0 \pm 4.2 \mathrm{~kg} / \mathrm{m}^{2}\right)$ compared to the BMI of men with normal sperm concentration $(26.8 \pm 4.0)$. Within the group of azoospermic men, those who produced semen volume $<1.5 \mathrm{ml}$, (WHO cut-off point, $(\mathrm{WHO}, 2000))$ were significantly $(\mathrm{t}=3.01$; $\mathrm{P}$-value $=0.002)$ older $(46.0 \pm$ 
Table 1. Anthropometric and sperm concentration characteristics of study participants.

\begin{tabular}{|c|c|c|c|c|c|c|c|c|c|c|c|c|c|c|c|c|c|c|}
\hline \multirow{3}{*}{ Variable } & \multirow{3}{*}{ Item } & \multirow{3}{*}{ Total (\%) } & \multicolumn{4}{|c|}{$\begin{array}{l}\text { Sperm concentration } \\
\times 10^{6} / \mathrm{ml}\end{array}$} & \multirow{3}{*}{$\chi^{2}$} & \multirow{3}{*}{$\mathrm{P}$-value } & \multirow{3}{*}{$\begin{array}{l}\text { Odds } \\
\text { ratio }\end{array}$} & \multirow{3}{*}{$95 \%$ CI } & \multicolumn{4}{|c|}{$\begin{array}{l}\text { Sperm conc. } \geq \\
15 \times 10^{6} / \mathrm{ml} .\end{array}$} & \multicolumn{4}{|c|}{$\begin{array}{l}\text { Sperm conc. }= \\
0 \times 10^{6} / \mathrm{ml} 5 \mathrm{ml} .\end{array}$} \\
\hline & & & \multicolumn{2}{|c|}{$\geq 15$} & \multicolumn{2}{|c|}{0} & & & & & \multicolumn{2}{|c|}{$\begin{array}{c}\text { Semen } \\
\text { volume }<1.5\end{array}$} & \multicolumn{2}{|c|}{$\begin{array}{c}\text { Semen } \\
\text { volume } \geq 1.5\end{array}$} & \multicolumn{2}{|c|}{ Semen } & \multicolumn{2}{|c|}{$\begin{array}{c}\text { Semen } \\
\text { yolume }>15\end{array}$} \\
\hline & & & Freq. & $\%$ & Freq. & $\%$ & & & & & Freq. & $\%$ & Freq. & $\%$ & Freq. & $\%$ & Freq. & $\%$ \\
\hline \multirow{10}{*}{$\begin{array}{c}\text { Age } \\
\text { group } \\
\text { (yrs.) }\end{array}$} & $<30$ & $6(1.1)$ & 4 & 0.9 & 2 & 1.8 & - & - & - & - & 0 & 0.0 & 4 & 1.2 & 0 & 0.0 & 2 & 2.6 \\
\hline & $30-39.9$ & $192(34.2)$ & 153 & 33.8 & 39 & 35.8 & $0.07^{\star}$ & 0.80 & 0.51 & $0.09,2.89$ & 31 & 29.0 & 122 & 35.3 & 9 & 28.1 & 30 & 39.0 \\
\hline & $40-49.9$ & $271(48.2)$ & 224 & 49.4 & 47 & 43.1 & $0.23^{\star}$ & 0.64 & 0.42 & $0.07,2.36$ & 52 & 48.6 & 172 & 49.7 & 10 & 31.3 & 37 & 48.0 \\
\hline & $50-59.9$ & 84 (14.9) & 66 & 14.6 & 18 & 16.5 & $0.03^{*}$ & 0.87 & 0.55 & $0.09,3.22$ & 21 & 19.6 & 45 & 13.0 & 11 & 34.4 & 7 & 9.1 \\
\hline & $\geq 60$ & $9(1.6)$ & 6 & 1.3 & 3 & 2.8 & $0.31^{*}$ & 0.58 & 1.00 & $0.11,8.95$ & 3 & 2.8 & 3 & 0.9 & 2 & 6.2 & 1 & 1.3 \\
\hline & All & $\begin{array}{c}562 \\
(100.0)\end{array}$ & 453 & 80.6 & 109 & 19.4 & & & & & 107 & 77.0 & 346 & 81.8 & 32 & 23.0 & 77 & 18.2 \\
\hline & $\begin{array}{l}\text { Mean } \\
( \pm s d)\end{array}$ & $42.6(7.1)$ & \multicolumn{2}{|c|}{$42.6(7.0)$} & \multicolumn{2}{|c|}{$42.6(7.7)$} & & & & & \multicolumn{2}{|c|}{$44.5(7.7)^{!}$} & \multicolumn{2}{|c|}{$42.00(6.6) ! !$} & \multicolumn{2}{|c|}{$46.0(7.9)^{!}$} & \multicolumn{2}{|c|}{$41.1(7.1)^{! !}$} \\
\hline & Range & $23-68$ & \multicolumn{2}{|c|}{$23-68$} & \multicolumn{2}{|c|}{$28-62$} & & & & & \multicolumn{2}{|c|}{$30-67$} & \multicolumn{2}{|c|}{$23-68$} & $34-$ & 62 & \multicolumn{2}{|c|}{$28-61$} \\
\hline & $\mathrm{t}$-test $(\mathrm{F}$ & P-value) & & 0.12 & $(0.45)$ & & & & & & & 3.04 & $0.001)$ & & & $3.01(0$ & $0.002)$ & \\
\hline & t-test (I & P-value) & & & & & & & & & & $=-0$ & $5(0.1$ & & & $t=1.02$ & $2(0.16$ & \\
\hline & $18.5-24.9$ & 171 & 148 & 32.7 & 23 & 21.1 & - & - & - & - & 39 & 36.4 & 109 & 31.5 & 9 & 39.5 & 14 & 18.2 \\
\hline & $25.0-29.9$ & $294(52.3)$ & 234 & 51.6 & 60 & 64.2 & 3.60 & 0.05 & 1.65 & $0.98,2.78$ & 18 & 56.3 & 187 & 54.0 & 47 & 43.9 & 42 & 54.5 \\
\hline & $\geq 30$ & $97(17.3)$ & 71 & 15.7 & 26 & 23.9 & 7.39 & 0.007 & 2.37 & $1.26,4.42$ & 5 & 15.6 & 50 & 14.5 & 21 & 19.6 & 21 & 27.3 \\
\hline $\begin{array}{l}\text { BMI } \\
\text { group }\end{array}$ & All & $\begin{array}{c}562 \\
(100.0)\end{array}$ & 453 & 80.6 & 109 & 19.4 & & & & & 62 & 11.03 & 346 & 88.07 & 77 & 13.70 & 77 & 13.70 \\
\hline & $\begin{array}{l}\text { Mean } \\
( \pm s d)\end{array}$ & $27.0(4.1)$ & 26.8 & $(4.0)$ & 28.0 & (4.2) & & & & & 26.8 & (4.1) & 26.8 & (4.0) & 27.1 & (3.3) & 28.4 & (4.5) \\
\hline & Range & $18.5-70.0$ & 18.5 & -70.0 & 19.4 & 48.7 & & & & & 19.9 & -38.0 & 18.5 & -70.0 & $20.2-$ & 34.8 & 19.4 & 48.7 \\
\hline & $\mathrm{t}$-test ( $\mathrm{l}$ & P-value) & & -2.70 & $(0.004)$ & & & & & & & -0.11 & $(0.46)$ & & & -2.19 & $(0.02)$ & \\
\hline & Normal & $\begin{array}{c}452 \\
(49.83)\end{array}$ & & & & & & & & & & & & & & & & \\
\hline $\begin{array}{c}\text { Sperm } \\
\text { concentration }\end{array}$ & $0.1-14.0$ & $\begin{array}{c}346 \\
(38.15)\end{array}$ & & & & & & & & & & & & & & & & \\
\hline & 0 & $\begin{array}{c}109 \\
(12.02)\end{array}$ & & & & & & & & & & & & & & & & \\
\hline
\end{tabular}

7.9 vs. $41.1 \pm 7.1$ years $)$ and significantly $(\mathrm{t}=-2.19, \mathrm{P}$-value $=002)$ lighter $(27.1 \pm$ 3.3 vs. $28.4 \pm 4.5 \mathrm{~kg} / \mathrm{m}^{2}$ ) than those who produced semen volume of $\geq 1.5 \mathrm{ml}$. Men with normal sperm concentration who produced semen volume $<1.5 \mathrm{ml}$ were also significantly older (44.5 \pm 7.7 years) than men who produced semen volume $\geq 1.5 \mathrm{ml}(\mathrm{t}=3.04, \mathrm{P}$-value $=0.001)$.

The mean semen volume (ml.) and liquefaction time (mins.) among the azoospermic men and those with normal sperm concentration is illustrated in Table 2. Overall, there was no significant difference in the mean semen volume or liquefaction time. However, when considered from the perspective of different age groups, there were substantial alterations $(t=3.13, \mathrm{P}$-value $=0.001, \mathrm{t}=3.88$, 


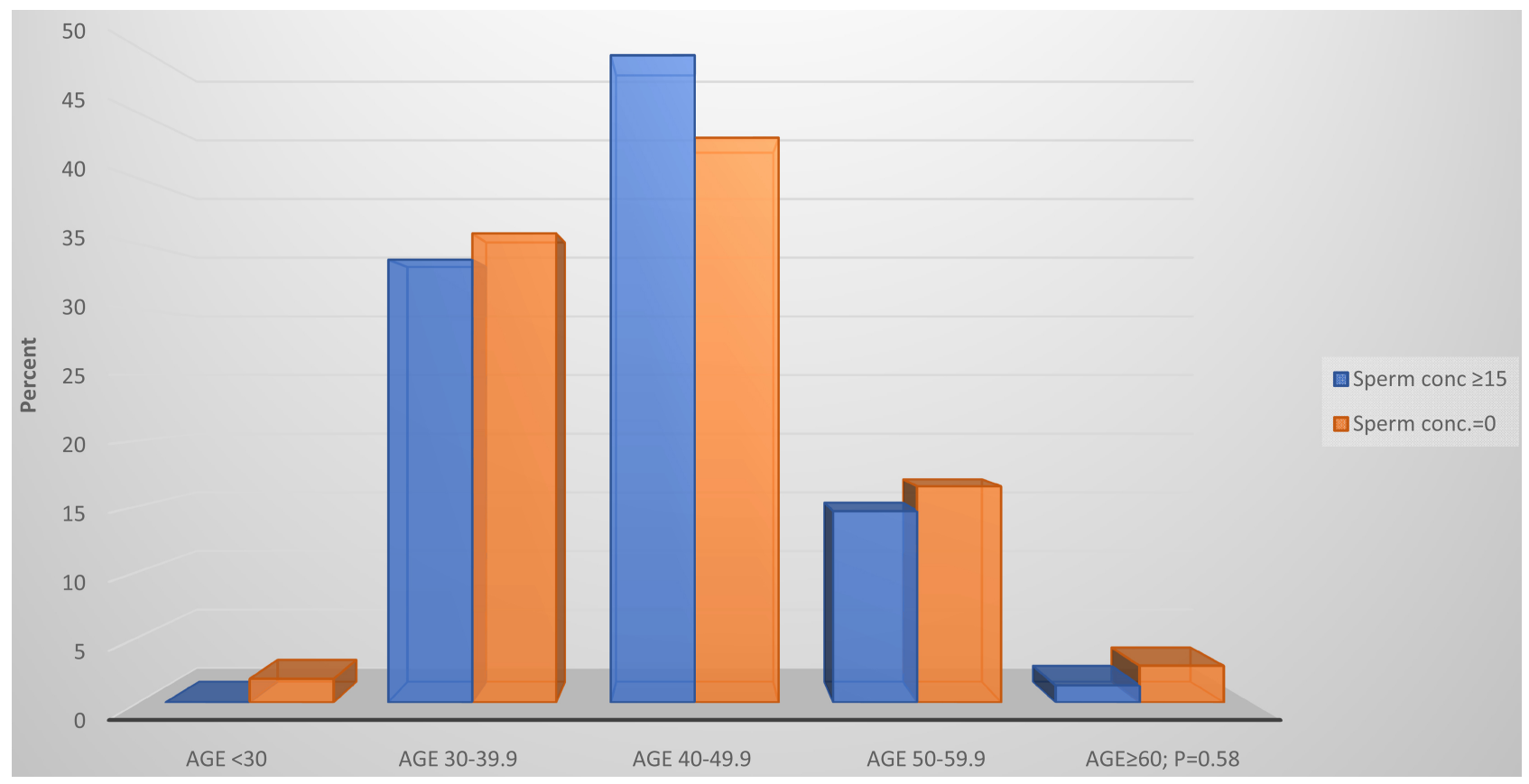

Figure 1. Percent distribution of proportion of men with normal sperm concentrations and with azoospermia by age (years). Compared with patients aged $<30$ years, there was no significant difference in the proportion of patients aged $30-39.9$ years $\left(\chi^{2}=\right.$ 0.07 , P-value $=0.80)$, those aged $40-49.9$ years $\left(\chi^{2}=0.23, \mathrm{P}\right.$-value $\left.=0.64\right)$, those age $50-59.9$ years $\left(\chi^{2}=0.03, \mathrm{P}\right.$-value $\left.=0.87\right)$ and those aged $\geq 60\left(\chi^{2}=0.31, \mathrm{P}\right.$-value $\left.=0.58\right)$ with sperm concentration of $15 \times 10^{6} / \mathrm{ml}$ and those with azoospermia.

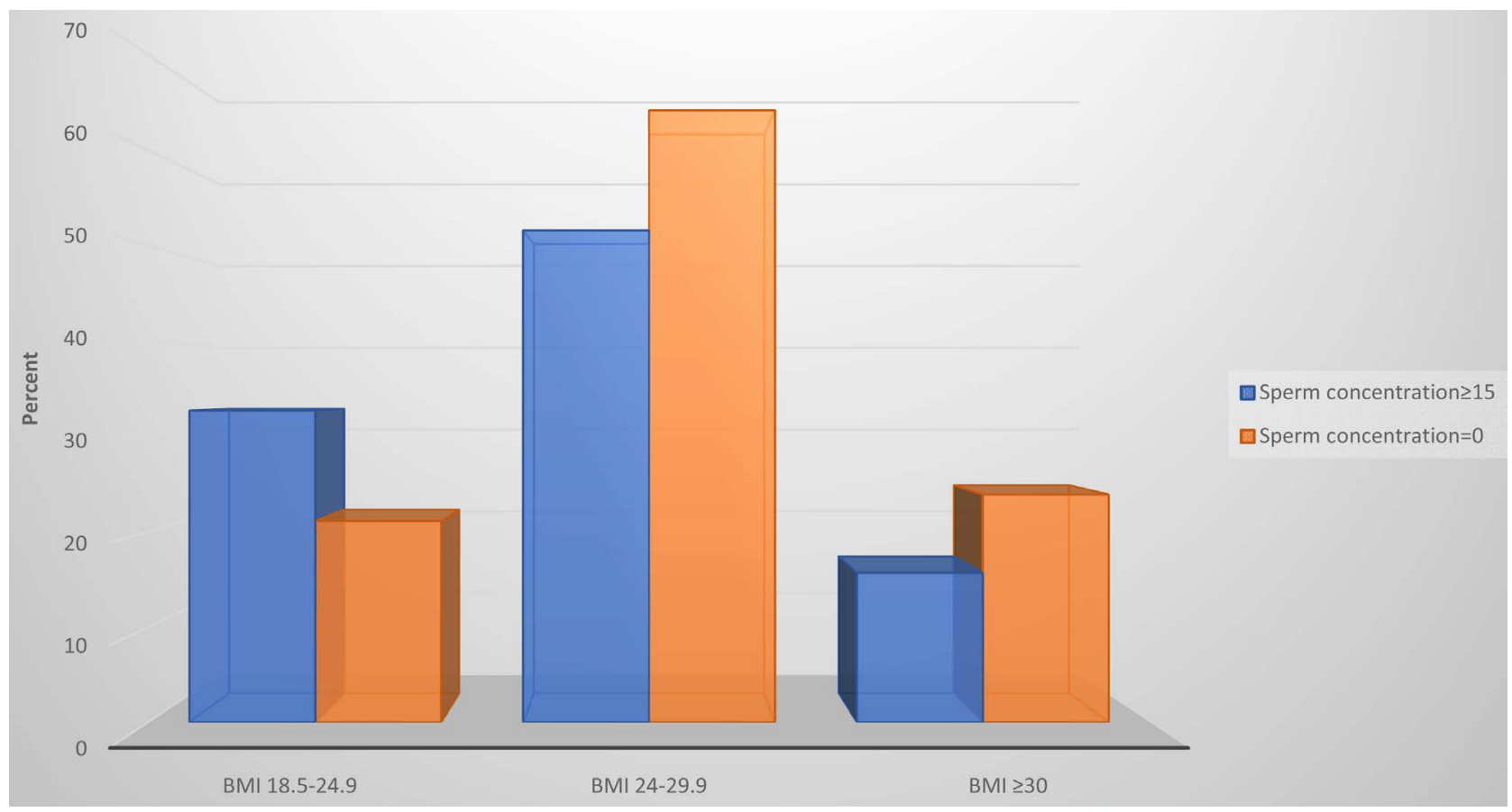

Figure 2. Percent distribution of proportion of men with normal sperm concentrations and with azoospermia by BMI. Overweight patients (BMI 25 - 29.9) and obese patients (BMI $\geq 30)$ were, respectively, 1.65 times $\left(\chi^{2}=3.60, \mathrm{P}\right.$-value $\left.=0.05, \mathrm{OR}=1.65\right)$ and 2.37 times $\left(\chi^{2}=7.39\right.$, P-value $=0.007$; OR 2.37) more likely to be azoospermic than patients with normal BMI (18.5 - 24.9).

$\mathrm{P}$-value $=0.0001)$ in the means of semen volumes of azoospermic men aged 30 39.9 years $(1.90 \pm 0.78)$ and those aged $50-59.9$ years $(1.16 \pm 0.62)$ compared 
Table 2. Mean semen volume (mls.) and liquefaction time (mins.) of azoospermic and normal men by age and by BMI of participants.

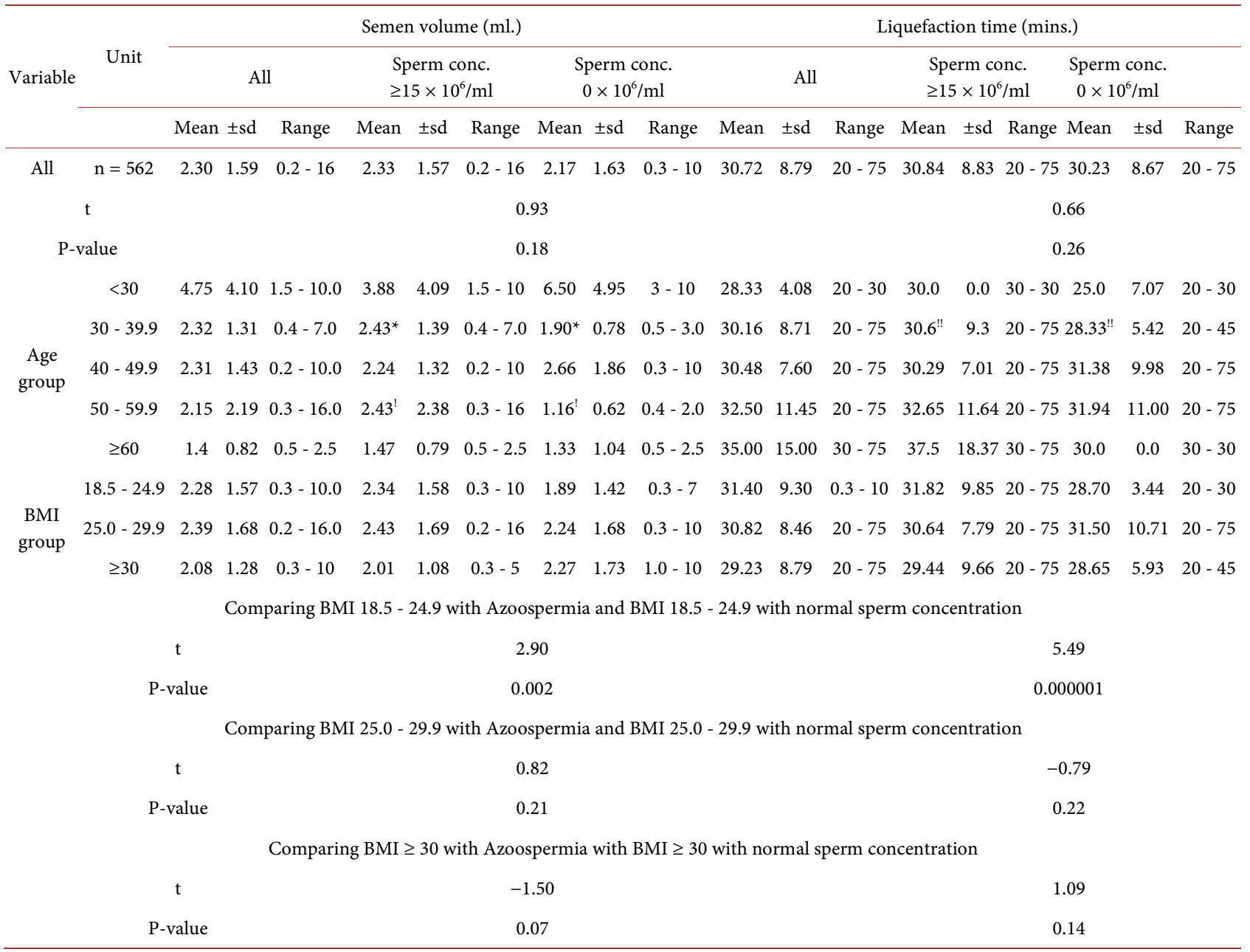

$*(\mathrm{t}=3.15, \mathrm{P}$-value $=0.001) ;{ }^{\prime}(\mathrm{t}=3.88, \mathrm{P}$-value $=0.0001) ; "(\mathrm{t}=1.98, \mathrm{P}$-value $=0.03)$.

with mean semen volumes of normal men aged 30-39.9 years $(2.43 \pm 1.39)$ and those aged 50 - 59.9 years $(2.43 \pm 2.38)$.

Also, overall, there was no significant difference in the mean liquefaction time of azoospermic and normal men but when categorized by age group, the mean liquefaction time of azoospermic men aged 30-39.9 years (28.33 \pm 5.42$)$ was significantly lower $(t=1.98, \mathrm{P}$-value $=0.03)$ than that of normal men in the same age group.

Furthermore, the mean semen volume of normal weight azoospermic men $(1.89 \pm 1.42 \mathrm{mls})$ was significantly lower $(t=2.90, \mathrm{P}$-value $=0.002)$ than that of their counterparts with normal sperm concentration $(2.34 \pm 1.58 \mathrm{ml}$.) and the mean liquefaction time of normal weight azoospermic men (28.70 \pm 3.44 mins.) was significantly lower $(t=5.49$, P-value $=0.000001)$ than that of their counterparts with normal sperm concentration (31.82 \pm 9.85 mins.).

Though there was no significant variation in the mean pus cell count of men with normal sperm count and those with azoospermia, overall, obese men with 
no sperm were 2.11 times and 3.75 times as likely to have pyospermia of 1 $3 / \mathrm{hpf}$ and of 4 - 10/hpf respectively compared to men with normal sperm concentration. Overweight men with no sperm were 1.71 times and 3.33 times more likely to have pyospermia of $1-3 / \mathrm{hpf}$ and of $4-10 / \mathrm{hpf}$ respectively, compared to men with normal sperm concentration (Table 3 ).

The proportion of men in each age group that presented with azoospermia relative to their body mass index is as illustrated in Table 4 and in Figure 3 and Figure 4. In age group $<30$, overweight men were approximately twice as likely to have azoospermia $(\mathrm{OR}=1.79,95 \% \mathrm{CI}: 0.77,4.19)$ and were at higher risk $(\mathrm{RR}=$ 1.61, 95\% CI: $0.79,3.27)$ compared to normal weight man. In the same age group, obese men were 2.13 times as likely to develop azoospermia (OR $=2.13$, 95\% CI: $0.73,6.19)$ and were at even higher risk ( $\mathrm{RR}=1.84,95 \% \mathrm{CI}: 0.78,4.29)$ than normal weight men in the same age group. The risk of azoospermia in those aged 40 - 49 years increased from 1.35 among overweight men $(R R=1.35$, $95 \% \mathrm{CI}: 0.68,2.70)$ to $2.04(\mathrm{RR}=2.04,95 \% \mathrm{CI}: 0.97,5.87)$ among the obese. Obese men in this age group were approximately $2 \frac{1}{2}$ times more likely to develop

Table 3. Proportion of patients with low and high levels of pus cells per high power field among those with normal and no sperm cells relative to their age and BMI.

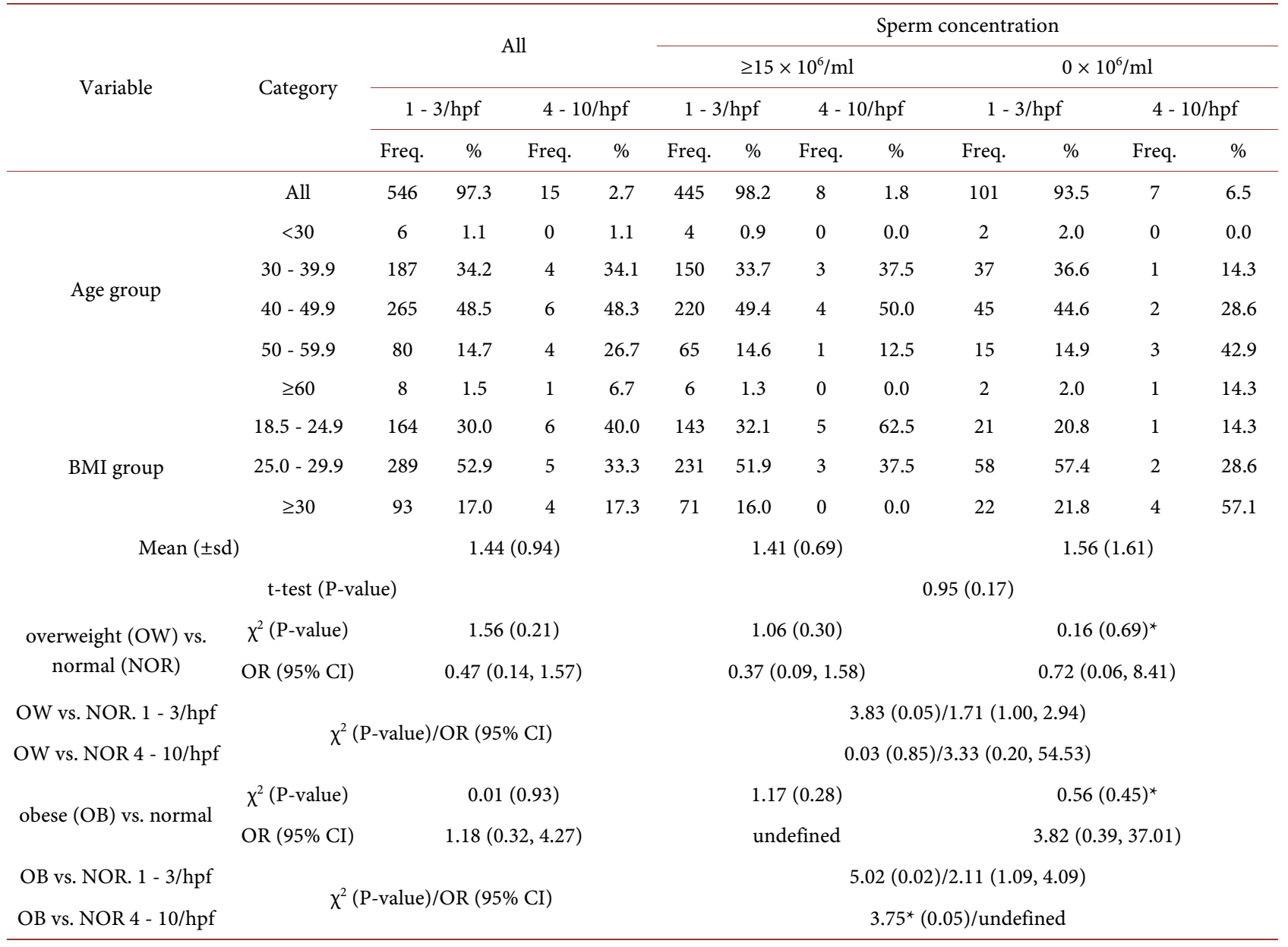

*Fisher's exact test. 
Table 4. Proportion of men in each age group that presented with azoospermia relative to their BMI.

\begin{tabular}{|c|c|c|c|c|c|c|c|c|c|c|c|c|c|}
\hline \multirow{4}{*}{ Variable } & \multirow{4}{*}{ Item } & \multicolumn{6}{|c|}{ Sperm concentration $\geq 15 \times 10^{6} / \mathrm{ml}$} & \multicolumn{6}{|c|}{ Sperm concentration $=0 \times 10^{6} / \mathrm{ml}$} \\
\hline & & \multicolumn{12}{|c|}{ BMI $\left(\mathrm{kg} / \mathrm{m}^{2}\right)$} \\
\hline & & \multicolumn{2}{|c|}{ Normal } & \multicolumn{2}{|c|}{ Overweight } & \multicolumn{2}{|c|}{ Obese } & \multicolumn{2}{|c|}{ Normal } & \multicolumn{2}{|c|}{ Overweight } & \multicolumn{2}{|c|}{ Obese } \\
\hline & & Freq. & $\%$ & Freq. & $\%$ & Freq. & $\%$ & Freq. & $\%$ & Freq. & $\%$ & Freq. & $\%$ \\
\hline \multirow{5}{*}{$\begin{array}{l}\text { Age group } \\
\text { (years) }\end{array}$} & $<30$ & 2 & 1.3 & 2 & 0.9 & 0 & 0.0 & 0 & 0.0 & 1 & 1.7 & 1 & 3.5 \\
\hline & $30-39$ & 55 & 37.2 & 75 & 32.0 & 23 & 32.4 & 9 & 39.1 & 22 & 36.7 & 8 & 30.8 \\
\hline & $40-49$ & 70 & 47.3 & 113 & 48.3 & 41 & 57.7 & 10 & 43.5 & 23 & 38.3 & 14 & 53.9 \\
\hline & $50-59$ & 20 & 13.5 & 39 & 16.7 & 7 & 9.9 & 3 & 13.0 & 12 & 20.0 & 3 & 11.5 \\
\hline & $\geq 60$ & 1 & 0.7 & 5 & 2.1 & 0 & 0.0 & 1 & 4.4 & 2 & 3.3 & 0 & 0.0 \\
\hline
\end{tabular}

Comparing azoospermia in age group $<30$

Overweight vs. normal

$\chi^{2}=0.05^{\star}, \mathrm{P}$-value $=0.82, \mathrm{OR}=$ undefined, $95 \% \mathrm{CI}$ : undefined

Obese vs. normal

$\chi^{2}=0.19^{\star}, \mathrm{P}$-value $=0.67, \mathrm{OR}=$ undefined, $95 \% \mathrm{CI}$ : undefined

Comparing azoospermia in age group $30-39.9$

$\begin{array}{cl}\text { Overweight vs. normal } & \chi^{2}=1.84, \text { P-value }=0.17, \mathrm{OR}=1.79,95 \% \text { CI: } 0.77,4.19 ; \mathrm{RR}=1.61,95 \% \text { CI: } 0.79,3.27 \\ \text { Obese vs. normal } & \chi^{2}=1.96, \text { P-value }=0.16, \mathrm{OR}=2.13,95 \% \text { CI: } 0.73,6.19 ; \mathrm{RR}=1.84,95 \% \text { CI: } 0.78,4.29\end{array}$

Comparing azoospermia in age group $40-49.9$

Overweight vs. normal $\quad \chi^{2}=0.76, \mathrm{P}$-value $=0.38, \mathrm{OR}=1.42,95 \%$ CI: $0.64,3.17 ; \mathrm{RR}=1.35,95 \%$ CI: $0.68,2.70$

Obese vs. normal $\quad \chi^{2}=3.74, \mathrm{P}$-value $=0.05, \mathrm{OR}=2.39,95 \%$ CI: $0.97,5.87 ; \mathrm{RR}=2.04,95 \%$ CI: $0.98,4.25$

Comparing azoospermia in age group $50-59.9$

Overweight vs. normal

$\chi^{2}=0.53^{*}, \mathrm{P}$-value $=0.47, \mathrm{OR}=2.05,95 \%$ CI: $0.52,8.11 ; \mathrm{RR}=1.80,95 \%$ CI: $0.56,5.79$

Obese vs. normal

$\chi^{2}=0.45^{*}$, P-value $=0.50, \mathrm{OR}=2.86,95 \%$ CI: $0.46,17.58 ; \mathrm{RR}=2.30,95 \%$ CI: $0.56,9.49$

Comparing azoospermia in age group $\geq 60$

Overweight vs. normal

$\chi^{2}=0.08^{*}, \mathrm{P}$-value $=0.78, \mathrm{OR}=0.40,95 \%$ CI: $0.02,10.02 ; \mathrm{RR}=0.57,95 \%$ CI: $0.09,3.51$

Obese vs. normal

$\chi^{2}=0.26^{\star}, \mathrm{P}$-value $=0.61, \mathrm{OR}=$ undefined, $95 \% \mathrm{CI}$ : undefined; $\mathrm{OR}=$ undefined, $95 \% \mathrm{CI}$ : undefined

azoospermia compared to normal weight men in the same age group. Likewise, the risk of azoospermia in those aged 50 - 59 years was higher among the overweight patients $(\mathrm{RR}=1.80,95 \% \mathrm{CI}: 0.56,5.79)$ and among obese patients $(\mathrm{RR}=$ 2.30, 95\% CI: $0.56,9.49)$ when compared with normal weight men in the same age category. There was no statistically significant difference in the proportion of men aged 60 years and above with and without azoospermia regardless of their BMI.

Multivariate regression analysis (Table 5) shows that Age, BMI, Semen volume and Pus cells, explained an insignificant $0.71 \%$ of the differences observed in sperm concentration of study subjects and only BMI had a negative but significant correlation coefficient with sperm concentration (Coef. $=-0.48$, Std. Err. $=$ 0.25$, F-statistics $=-1.92, \mathrm{P}$-value $=0.05,95 \% \mathrm{CI}:-0.96,0.10)$.

\section{Discussion}

Infertility, especially of male, in sub-Saharan Africa presents discrete and multifaceted worries far beyond those that the developed nations are used to. Although, 


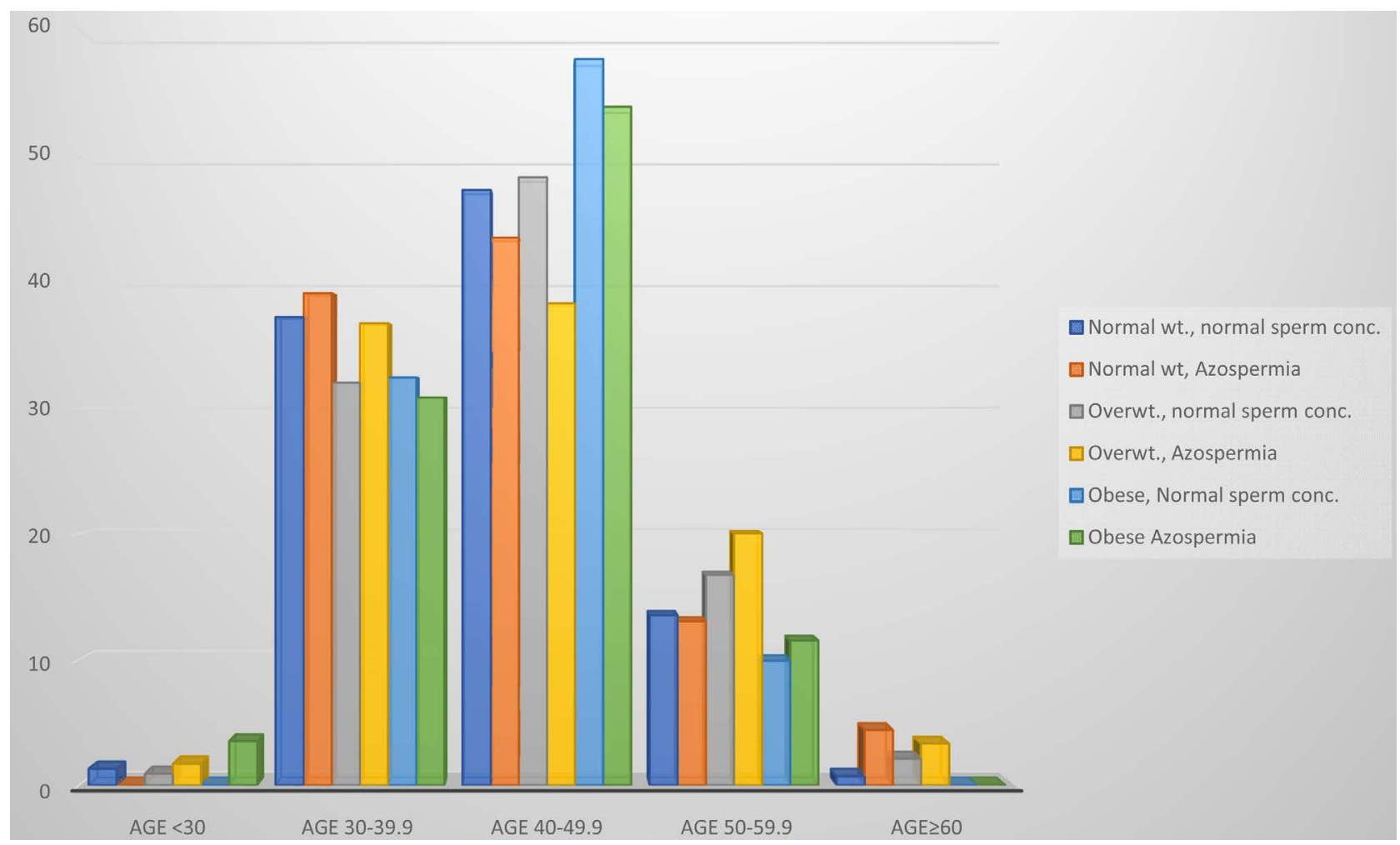

Figure 3. Percent distribution of patients with normal sperm concentration (conc.) and with azoospermia in each age group relative to BMI of normal weight (wt.), overweight (overwt.) and obese. Overweight patients aged 30 - 39.9 years were 1.70 more likely to be azoospermic compared to normal weight patients in the same age $\left(\chi^{2}=1.84\right.$, P-value $\left.=0.17, \mathrm{OR}=1.79,95 \% \mathrm{CI}: 0.77,4.19\right)$. Obese patients aged 30 - 39.9 years were 2.13 times more likely to be azoospermic compared to normal patients in the same age $\left(\chi^{2}=\right.$ 1.96 , P-value $=0.16, \mathrm{OR}=2.13,95 \% \mathrm{CI}: 0.73,6.19)$. Similar pattern in seen in other age groups except age $<30$ and age $\geq 60$ years.

it may seem that sub-Saharan Africa is faced with over-population, which should be tackled instead of infertility which is expensive in its management, however, the burden of male infertility affects not only the man concerned but extends to his spouse and touches upon the male ego, the deepest being of the couple, their family members, their community and other institutions. The consequences of male infertility include severe economic depression, social isolation, mental disturbance, discrimination, stigmatization, suicide and murder. This problem is so intense that it is not often talked about openly though many men need medical support in this regard so as to help themselves and help their wives.

There are a number of major findings in this study which, as far as we know, may be the first of its kind in sub-Saharan Africa. Firstly, the $12.0 \%$ prevalence of azoospermia in the overall study group accords with the $10 \%-15 \%$ quoted by Gudeloglu and colleague [7] but much less than the $40 \%$ reported by Bashed et al. [24] in Bangladesh. Earlier and recent studies have also shown decline in some semen quality with age [25] [26] such as lower ejaculate volume and sperm motility [27] [28] and increased paternal age with sperm quality [29]. There appears to be a phenomenon of gradual reduction in sperm quality of Africans as reported in a recent study [30].

Some earlier studies have reported a gradual decline in sperm quality in 


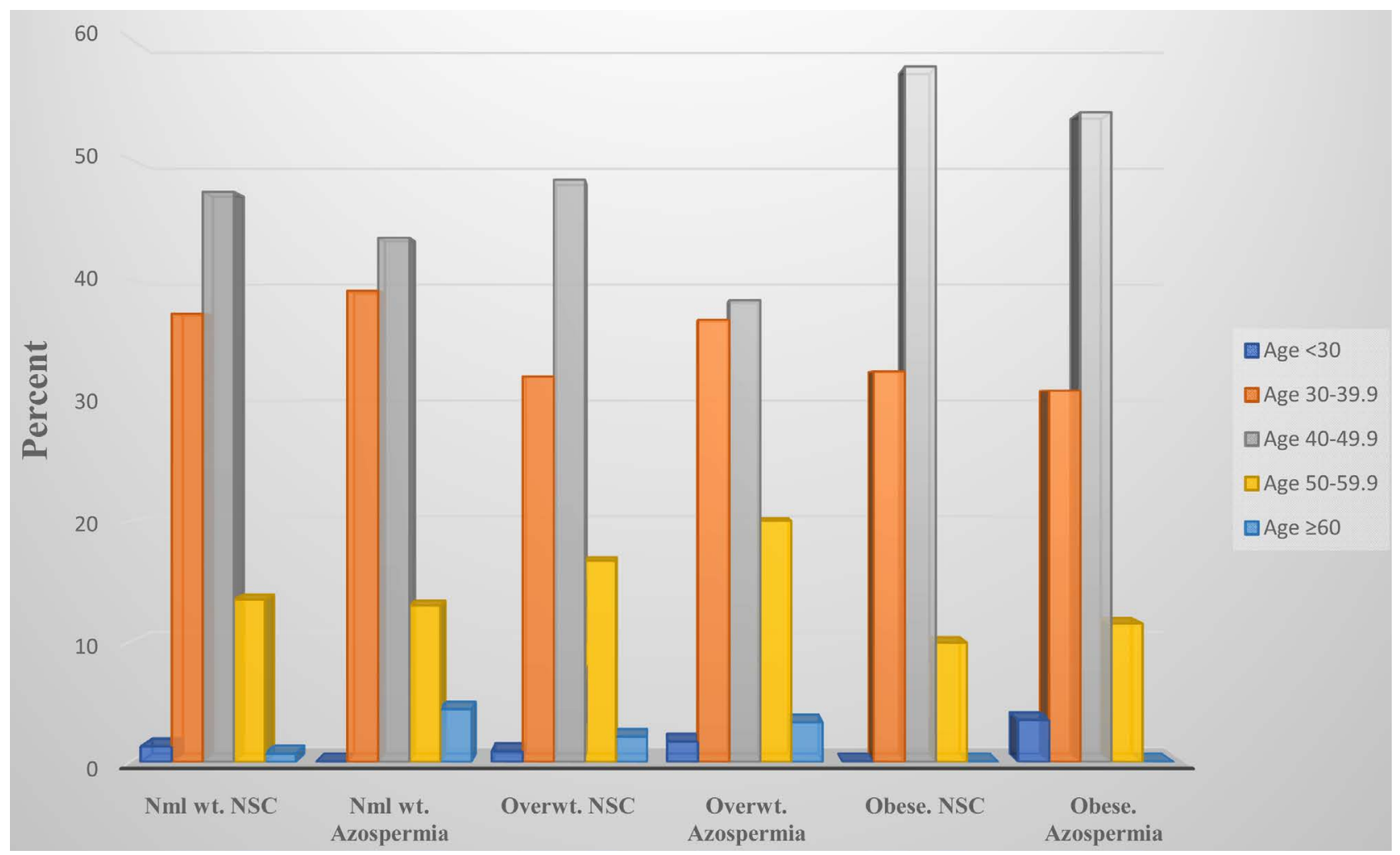

Figure 4. Percent distribution of patients with normal sperm count (NSC) and with azoospermia in each BMI category of normal weight ( $\mathrm{Nml}$ wt.), overweight (Overwt.) and obese relative to age group. The risk of azoospermia in those aged 40 49 years increased from 1.35 among overweight men $(\mathrm{RR}=1.35,95 \% \mathrm{CI}: 0.68,2.70)$ to $2.04(\mathrm{RR}=2.04,95 \% \mathrm{CI}: 0.97,5.87)$ among the obese.

Table 5. Multivariate regression analysis with sperm concentration as dependent variable and age, BMI, volume and pus cells as independent variables.

\begin{tabular}{cccccc}
\hline $\begin{array}{c}\text { Equation } \\
\text { Sperm concentration }\end{array}$ & Obs & $\mathrm{R}^{2}$ & F-statistics & P-value & \\
\hline & 561 & 0.0071 & 0.9900 & 0.4124 & \\
\hline Age & -0.03 & 0.14 & -0.20 & 0.84 & $-0.31,0.25$ \\
BMI & -0.48 & 0.25 & -1.92 & 0.05 & $-0.96,0.10$ \\
Semen volume & -0.00 & 0.64 & -0.00 & 1.00 & $-1.26,1.26$ \\
Pus cells & -0.46 & 1.09 & -0.42 & 0.67 & $-2.60,1.68$ \\
_cons & 47.47 & 9.30 & 5.11 & 0.000 & $29.21,65.73$ \\
\hline
\end{tabular}

developed world since 1970s, with particular reference to sperm count [31] [32]. A recent study has suggested that altered seminal parameters in middle aged men are correlated with lower urinary tract syndrome, prostate enlargement and/or bladder outlet obstruction [33]. The possible causes for azoospermia among indigenous Black African men may not be different from the causes among their Caucasian counterparts, which are: congenital factors, acquired urogenital abnormalities, urogenital infections, increased scrotal temperature, endocrine disturbances, genetic abnormalities, immunological factors, systemic diseases, exogenous factors, 
lifestyle factors (such as obesity, smoking, drugs, anabolic steroids) and idiopathic factors [34]. Incidentally, there was no significant alteration in the ages of men with normal sperm concentration and those with no sperm. However, when $\mathrm{BMI}$ in each age group was calculated, it was obvious that there were significant alterations in those with and without sperms. Studies should not conclude on either age or BMI alone but take both into consideration when assessing sperm parameters.

Another key finding in this study, similar to what some other studies reported, was the significant difference, not only in age specifically, but in the combination of Age and BMI of men with no sperm compared to those with normal sperm concentration. Obese men between the ages of 30 - 59.9 years were $2.13-2.86$ times more likely to have no sperms while overweight men in the same range were between 1.42 - 2.05 as likely to have no sperms compared to their younger counterparts. The 1.84 relative risk of azoospermia observed among obese men aged 30 - 39.9 years observed in this study was slightly higher than the 1.81 reported by Sermondale, et al. [35] and the relative risk of 2.04 observed among obese men aged 40 - 49.9 years in our study was even higher. This suggests that obesity and azoospermia are both probably Age/BMI-dependent. It is likely that obesity fast-tracks reduction in sperm count as age advances to about 60 years, at least in indigenous Black Africans, after which no statistical difference was observed between age, body mass index and azoospermia. Obesity impacts male infertility in more than one way such as elevated risk of erectile dysfunction [35] [37]; hypogonadotropic hyperestrogenic hypogonadism due to aromatization of steroids in estrogens in peripheral tissues [38]; direct alterations of spermatogenesis and Sertoli cell function [39]; hip, abdominal and scrotal fat tissue accumulation leading to the increase of scrotal temperature [40] and accumulation of toxic substances and liposoluble endocrine disruptors in fatty tissue [41].

One of the most interesting findings in this study was the gradual increase in relative risk of azoospermia as age and BMI increases. The RR (OR) of 1.11 (1.01, $1.21)$ among overweight men and of $1.28(1.06,1.55)$ among obese reported by Sermondale et al. [42] were lower than the $1.61(0.79,3.27)$ and $1.84(0.78,4.29)$ observed among overweight men aged $<30$ years in our study or the $1.84(0.78$, 4.29 ) among obese men in the same age group. This risk was even higher at 2.04 $(0.97,5.87)$ among obese men aged $40-49$ years. There is a probability that association between obesity and azoospermia is multifactorial. Studies have proposed varying pathophysiological hypotheses for such derangement in sperm parameter among which are the changes in the hypothalamic-pituitary-gonadal axis, the aromatization of steroids to estrogens in peripheral tissue leading to hypogonadotropic hyperestrogenic hypogonadism [38], significant decrease in total and free testosterone levels and increase in estradiol $\left(\mathrm{E}_{2}\right)$ that combine to have deleterious effects on spermatogenesis [42]. Other studies have illustrated a decrease of sex hormone-binding globulin among obese men, notably mediated by hyperinsulinemia, emphasizing the negative feedback effect of elevated total 
$\mathrm{E}_{2}$ levels [43]. Obesity is also associated with an increase in endorphins leading to both lower LH pulse amplitude and GnRH production [44].

Finally, the mean pyospermia of $1.56 \pm 1.61$ found among men with no sperm in this study was much lower than the $3.25 \pm 0.26$ found among azoospermic men in Pakistan and the 1.41 (0.69) found in men with normal sperm count was also lower than the $2.98 \pm 0.04$ found in proven fathers [45]. Pus in semen is not often considered in fertilization work-up but it could be one of the most important causes of male infertility, though its role remains contentious [45]. Pyospermia possibly has a deleterious effect not only on semen parameters but also in Artificial Reproduction Technique such as In-vitro fertilization (IVF), especially when pus in sperm is not considered. The report of Schirren [46] suggests that pus in sperm increases reactive oxygen species (ROS) which may trigger sperm damage or DNA fragmentation, causing substantial increase in male infertility.

\section{Conclusion}

To conclude, this study finds that the relatively high prevalence and risk of azoospermia among indigenous Black Africans is associated more with overweight and obesity and probably less with age. Liquefaction time was shorter among men without sperm compared with those with normal sperm concentration. These data strongly suggest that excessive increase in body weight possibly plays a key role in sperm non-production. Obese azoospermic men were about 4 times as likely to have high pus cells in semen than normal weight azoospermic men. The pathophysiology of azoospermia in men aged $<30$ may be different from that in older men. Periodic national longitudinal studies and randomized controlled trials on male infertility are urgently required.

\section{Strengths and Limitations}

This study has some strengths and weaknesses that need to be discussed. One of the strengths is that collection of semen samples was strictly adhered to by everyone. This may be because each couple was well-counseled by experts on at least two occasions before sample collection. Most of the patients gained the confidence of the consultants and felt free to abide by the regulations of the Fertility Center. Also, the height and weight of each patient was measured and the body mass index was calculated, not volunteered by the patients. The Fertility Center uses up-to-date laboratory equipment for semen analysis and in almost all cases each analysis was on two consecutive samples. Another strength of the paper is that there were ample number of patients with overweight and obesity. The same study criteria were used for all the patients.

Limitations of the study were that the semen was collected in three different locations and the samples were analyzed in three different laboratories of the same organization with the possibility of inter-laboratory variation. However, almost all the samples were examined twice with quite insignificant difference in 
the results. Also, the study was facility-based and may not have reflected the exact prevalence of azoospermia in the population. Because confounding factors were many-tobacco use, narcotic drug use, alcohol consumption, caffeine intake, current or past herbal or orthodox medication use, current or past lower urinary tract infection, current or past systemic illnesses such as renal, cardiac and metabolic diseases, current or previous occupational exposure to petrochemicals, long distance driving etc.- they were not singly or collectively taken into consideration in the study. In addition, there were no underweight men or morbidly obese men in the study.

\section{Authors Contribution}

ABA conceived of the study, participated in its design, and helped to draft the manuscript. BMA participated in its design, performed the statistical analysis, and drafted the manuscript. VDA, IO, OB, HA, and AA handled the recruitment of patients, sample collection, and supervised the clinical aspects of the work. AA supervised all laboratory work. All authors read and approved the final manuscript.

\section{Competing Interest}

All authors declare no competing interests.

\section{References}

[1] Boivin, J., Bunting, L., Collins, J.A. and Nygren, K.G. (2007) International Estimates of Infertility Prevalence and Treatment-Seeking: Potential Need and Demand for Infertility Medical Care. Human Reproduction, 22, 1506-1512. https://doi.org/10.1093/humrep/dem046

[2] Bashed, M.A. (2011) Male Infertility. Bangladesh Institute of Medical Science (BIMS), Dhaka, Bangladesh. http://www.bims-bd.com/male_infertility.htm

[3] World Health Organization (2000) WHO Manual for the Standardized Investigation and Diagnosis of the Infertile Couple. Cambridge University Press, Cambridge.

[4] Jarow, J.P., Espeland, M.A. and Lipshultz, L.I. (1989) Evaluation of the Azoospermic Patient. Journal of Urology, 142, 62-65. https://doi.org/10.1016/S0022-5347(17)38662-7

[5] Jungwirth, A., Diemer, T., Dohle, G.R., Giwercman, A., Kopa, Z., Krausz, C. and Tournaye, H. (2014) Guidelines on Male Infertility. European Association of Urology, Arnhem. http://www.uroweb.org/guidelines/online-guidelines/

[6] Cocuzza, M., Alvarenga, C. and Pagani, R. (2013) The Epidemiology and Etiology of Azoospermia. Clinics, 68, 15-26. https://doi.org/10.6061/clinics/2013(Sup01)03

[7] Gudeloglu, A. and Parekattil, S.J. (2013) Update in the Evaluation of the Azoospermic Male. Clinics, 68, 27-34. https://doi.org/10.6061/clinics/2013(Sup01)04

[8] Kumar, R. (2008) Reproductive Tract Tuberculosis and Male Infertility. Indian Journal of Urology, 24, 392-395. https://doi.org/10.4103/0970-1591.42624

[9] Ekwere, P.D. (1989) Filarial Orchitis: A Cause of Male Infertility in the Tropics-Case Report from Nigeria. Central African Journal of Medicine, 35, 456-460.

[10] Pasquali, R., Pelusi, C., Genghini, S., Cacciari, M. and Gambineri, A. (2003) Obesity 
and Reproductive Disorders in Women. Human Reproduction Update, 9, 359-372. https://doi.org/10.1093/humupd/dmg024

[11] Oates, R.D. (2008) The Genetic Basis of Male Reproductive Failure. Urologic Clinics of North America, 35, 257-270. https://doi.org/10.1016/j.ucl.2008.01.015

[12] Ajayi, A., Ajayi, V., Biobaku, O., Oyetunji, I., Aikhuele, H. and Afolabi, B.M. (2017) Awareness, Knowledge and Perception of in Vitro Fertilization among Final-Year Medical Students in South-West Nigeria. International Journal of Pregnancy \& Child Birth, 2, Article ID: 00007.

[13] Sermondade, N., Faure, C., Fezeu, L., Levy, R. and Czernichow, S. (2012) Obesity and Increased Risk for Oligozoospermia and Azoospermia. Archives of Internal Medicine, 172, 440-442. https://doi.org/10.1001/archinternmed.2011.1382

[14] Macdonald, A.A., Stewart, A.W. and Farquhar, C.M. (2013) Body Mass Index in Relation to Semen Quality and Reproductive Hormones in New Zealand Men: A Cross-Sectional Study in Fertility Clinics. Human Reproduction, 28, 3178-3187. https://doi.org/10.1093/humrep/det379

[15] Gupta, N. (2002) Infertility: Planning a Prototype Action Plan in the Existing Health Care System. Journal of the Indian Medical Association, 100, 391-394.

[16] Nguyen, R.H., Wilcox, A.J., Skjaerven, R. and Baird, D.D. (2007) Men's Body Mass Index and Infertility. Human Reproduction, 22, 2488-2493.

https://doi.org/10.1093/humrep/dem139

[17] Ramlau-Hansen, C.H., Thulstrup, A.M., Nohr, E.A., Bonde, J.P., Sorensen, T.I., et al. (2007) Subfecundity in Overweight and Obese Couples. Human Reproduction, 22, 1634-1637. https://doi.org/10.1093/humrep/dem035

[18] Sallmen, M., Sandler, D.P., Hoppin, J.A., Blair, A. and Baird, D.D. (2006) Reduced Fertility among Overweight and Obese Men. Epidemiology, 17, 520-523.

https://doi.org/10.1097/01.ede.0000229953.76862.e5

[19] Duits, F.H., van Wely, M., van der Veen, F. and Gianotten, J. (2010) Healthy Overweight Male Partners of Subfertile Couples Should Not Worry about Their Semen Quality. Fertility and Sterility, 94, 1356-1359. https://doi.org/10.1016/j.fertnstert.2009.05.075

[20] Eskandar, M., Al-Asmari, M., BabuChaduvula, S., Al-Shahrani, M., Al-Sunaidi, M., et al. (2012) Impact of Male Obesity on Semen Quality and Serum Sex Hormones. Advances in Urology, 2012, Article ID: 407601. https://doi.org/10.1155/2012/407601

[21] Relwani, R., Berger, D., Santoro, N., Hickmon, C., Nihsen, M., et al. (2011) Semen Parameters Are Unrelated to BMI But Vary with SSRI Use and Prior Urological Surgery. Reproductive Sciences, 18, 391-397. https://doi.org/10.1177/1933719110385708

[22] World Health Organization (2010) WHO Laboratory Manual for the Examination and Processing of Human Semen. 5th Edition, World Health Organization, Geneva.

[23] WHO. BMI Classification. http://www.who.int/gho/ncd/risk_factors/bmi_text/en/

[24] Bashed, M.A., Alam, G.M., Kabir, M.A. and Al-Amin, A.Q. (2012) Male Infertility in Bangladesh: What Serve Better-Pharmacological Help or Awareness Programme? International Journal of Pharmacology, 8, 687-694. https://doi.org/10.3923/ijp.2012.687.694

[25] Schwartz, D., Mayaux, M.J., Spira, A., Moscato, M.L., Jouannet, P., Czyglik, F. and David, G. (1983) Semen Characteristics as a Function of Age in 833 Fertile Men. Fertility and Sterility, 39, 530-535. https://doi.org/10.1016/S0015-0282(16)46946-3 
[26] Nieschlag, E., Lammers, U., Freischem, C.W., Langer, K. and Wickings, E.J. (1982) Reproductive Functions in Young Fathers and Grandfathers. The Journal of Clinical Endocrinology \& Metabolism, 55, 676-681. https://doi.org/10.1210/jcem-55-4-676

[27] Kuhnert, B. and Nieschlag, E. (2004) Reproductive Functions of the Ageing Male. Human Reproduction, 10, 327-339. https://doi.org/10.1093/humupd/dmh030

[28] Wyrobek, A.J., Eskenazi, B., Young, S., Arnheim, N., Tiemann-Boege, I., Jabs, E.W., et al. (2006) Advancing Age Has Differential Effects on DNA Damage, Chromatin Integrity, Gene Mutations, and Aneuploidies in Sperm. Proceedings of the National Academy of Sciences of the United States, 103, 9601-9606. https://doi.org/10.1073/pnas.0506468103

[29] Sharma, R., Agarwal, A., Rohra, V.K., Assidi, M., Abu-Elmagd, M. and Turki, R.F. (2015) Effects of Increased Paternal Age on Sperm Quality, Reproductive Outcome and Associated Epigenetic Risks to Offspring. Reproductive Biology and Endocrinology, 13, 35. https://doi.org/10.1186/s12958-015-0028-x

[30] Ajayi, B.A., Ajayi, V.D., Oyrtunji, I., Biobaku, O., Aikhuele, H., Adedamilola, A., Ayelehin, I. and Afolabi, B.M. (2017) Are Semen Parameters Worsening? Comparing Semen Parameters Ten Years Apart. Nigerian Medical Journal, 58, 72-75. http://www.nigeriamedj.com/aheadofprint.asp

[31] Carlsen, E., Giwercman, A., Keiding, N. and Skakkebaek, N.E. (1992) Evidence for Decreasing Quality of Semen during Past 50 Years. British Medical Journal, 305, 609-613. https://doi.org/10.1136/bmj.305.6854.609

[32] Swan, S.H. and Elkin, E.P. (1999) Declining Semen Quality: Can the Past Inform the Present? Bioessays, 21, 614-621. https://doi.org/10.1002/(SICI)1521-1878(199907)21:7<614::AID-BIES10>3.0.CO;2$\underline{B}$

[33] Ausmees, K., Korrovits, P., Timberg, G., Punab, K. and Mändar, R. (2013) Decline of Seminal Parameters in Middle-Aged Males Is Associated with Lower Urinary Tract Symptoms, Prostate Enlargement and Bladder Outlet Obstruction. International Brazilian Journal of Urology, 39, 727-740. https://doi.org/10.1590/S1677-5538.IBJU.2013.05.16

[34] Jungwirth, A., Diemer, T., Dohle, G.R., Giwercman, A., Kopa, Z., Krausz, C. and Tournaye, H. (2012) Guidelines for the Investigation and Treatment of Male Infertility. European Urology, 61, 159-163.

[35] Sermondade, N., Faure, C., Fezeu, L., Lévy, R., Czernichow, S. and on Behalf of the Obesity-Fertility Collaborative Group (2012) Obesity and Increased Risk for Oligozoospermia and Azoospermia. Archives of Internal Medicine, 172, 440-442. https://doi.org/10.1001/archinternmed.2011.1382

[36] Pasquali, R., Patton, L. and Gambineri, A. (2007) Obesity and Infertility. Current Opinion in Endocrinology, Diabetes and Obesity, 14, 482-487. https://doi.org/10.1097/MED.0b013e3282f1d6cb

[37] Bacon, C.G., Mittleman, M.A., Kawachi, I., Giovannucci, E., Glasser, D.B., et al. (2006) A Prospective Study of Risk Factors for Erectile Dysfunction.Journal of Urology, 176, 217-221. https://doi.org/10.1016/S0022-5347(06)00589-1

[38] Schneider, G., Kirschner, M.A., Berkowitz, R. and Ertel, N.H. (1979) Increased Estrogen Production in Obese Men. The Journal of Clinical Endocrinology \& Metabolism, 48, 633-638. https://doi.org/10.1210/jcem-48-4-633

[39] Winters, S.J., Wang, C., Abdelrahaman, E., Hadeed, V., Dyky, M.A. and Brufsky, A. (2006) Inhibin-B Levels in Healthy Young Adult Men and Prepubertal Boys: Is Obesity the Cause for the Contemporary Decline in Sperm Count Because of Fewer 
Sertoli Cells? Journal of Andrology, 27, 560-564.

https://doi.org/10.2164/jandrol.05193

[40] Shafik, A. and Olfat, S. (1981) Scrotal Lipomatosis. British Journal of Urology, 53, 50-54. https://doi.org/10.1111/j.1464-410X.1981.tb03128.x

[41] Magnusdottir, E.V., Thorsteinsson, T., Thorsteinsdottir, S., Heimisdottir, M. and Olafsdottir, K. (2005) Persistent Organochlorines, Sedentary Occupation, Obesity and Human Male Subfertility. Human Reproduction, 20, 208-215. https://doi.org/10.1093/humrep/deh569

[42] Sermondade, N., Faure, C., Fezeu, L., Shayeb, A.G., Bonde, J.P., Jensen, T.K., et al. (2013) BMI in Relation to Spermcount: An Updated Systematic Review and Collaborative Meta-Analysis. Human Reproduction, 19, 221-231. https://doi.org/10.1093/humupd/dms050

[43] Stellato, R.K., Feldman, H.A., Hamdy, O., Horton, E.S. and McKinlay, J.B. (2000) Testosterone, Sex Hormone-Binding Globulin, and the Development of Type 2 Diabetes in Middle-Aged Men: Prospective Results from the Massachusetts Male Aging Study. Diabetes Care, 23, 490-494. https://doi.org/10.2337/diacare.23.4.490

[44] Blank, D.M., Clark, R.V., Heymsfield, S.B., Rudman, D.R. and Blank, M.S. (1994) Endogenous Opioids and Hypogonadism in Human Obesity. Brain Research Bulletin, 34, 571-574. https://doi.org/10.1016/0361-9230(94)90142-2

[45] Khan, M.S., Mohammad, S.H., Deepa, F. and Tahir, F. (2012) Association between Pus Cells and Semen Parameters in Infertile Pakistani Males. Sultan Qaboos University Medical Journal, 12, 479-484. https://doi.org/10.12816/0003174

[46] Schirren, C. (1983) Textbook of Practical Andrology. Schireng AG, Hamburg, 17-31. 